\title{
Antimicrobial resistance acquisition after international travel in U.S. travelers
}

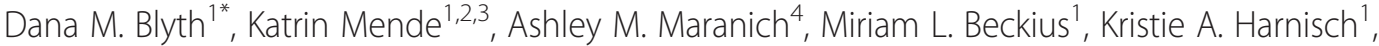 \\ Crystal A. Rosemann', Wendy C. Zera ${ }^{1,2,3}$, Clinton K. Murray ${ }^{1}$ and Kevin S. Akers ${ }^{1,5}$
}

\begin{abstract}
Background: Prior studies have shown an increase in multidrug-resistant (MDR) E. coli colonization from two percent in U.S.-based to $11 \%$ in deployed, healthy military personnel. It is unclear if colonization with MDR organisms occurs through deployment exposures or risks related to routine overseas travel. This study prospectively evaluates rates and risk factors associated with MDR gram-negative bacterial and methicillin-resistant $S$. aureus (MRSA) colonization after international travel.
\end{abstract}

Methods: Participants traveled internationally for five or more days. Pre- and post-travel, colonizing bacteria from oropharyngeal, nares, groin, and peri-rectal (PR) areas were collected using BD CultureSwab ${ }^{\mathrm{TM}} \mathrm{MaxV}(+)$. Identification and susceptibilities were done utilizing the BD Phoenix ${ }^{\text {TM }}$ Automated Microbiology System. Non-MDR pre- and posttravel MDR bacteria within a subject were compared by pulsed-field gel electrophoresis (PFGE). A questionnaire solicited demographics and potential risk factors for MDR acquisition.

Results: Of 58 participants, $41 \%$ were male and median age was 64 years. Pre- and post-travel swabs were obtained a median of ten and seven days before and after travel, respectively. Itineraries included 18 participants traveling to the Caribbean and Central America, 17 to Asia, 16 to Africa, 5 to Europe, 4 to South and North America. Seventeen of 22 travelers used atovaquone/proguanil for malaria prophylaxis. The only MDR organism isolated was extended-spectrum $\beta$-lactamase (ESBL)-producing E. coli in five (9\%) participants post-travel (all PR and unrelated by PFGE). There were no statistically significant associations between exposure risks and new ESBL-producing E.coli colonization. Of 36 participants colonized with E. coli pre- and post-travel, new resistance was detected: TMP/SMX in $42 \%$ of isolates $(p<0.01)$, tetracycline in $44 \%(p<0.01)$, and ampicillin-sulbactam in $33 \%(p=0.09)$. No participants were colonized with MRSA pre- or post-travel.

Conclusion: Consistent with prior studies, new antimicrobial resistance was noted in colonizing E. coli after international travel. Nine percent of participants acquired new strains of ESBL-producing E.coli without identified risks.

Keywords: ESBL-producing Enterobacteriaceae, Eschericia coli, Methicillin-resistant Staphylococcus aureus (MRSA), Travel

\section{Background}

Foreign travel has been increasingly recognized as a contributor to the global spread of extended-spectrum $\beta$ lactamase (ESBL)-producing Enterobacteriaceae [1-8]. The specific exposures during international travel that place people at risk for acquisition of multidrug-resistant (MDR) bacterial colonization are slowly being identified [7-9]. This

\footnotetext{
* Correspondence: Dana.M.Blyth.mil@mail.mil

${ }^{1}$ Infectious Disease Service, San Antonio Military Medical Center, JBSA Fort Sam Houston, 3551 Roger Brooke Drive, Houston, Texas 78234-4505, USA Full list of author information is available at the end of the article
}

increase in ESBL-producing Enterobacteriaceae (particularly E. coli) colonization has also been identified in healthy, deployed personnel during operations in Afghanistan [10]. Whether the risks associated with these increased rates are related to those of all international travelers or to risk factors particular to the deployed population remains to be answered. Outside the first 24 hours following injury, infections remain a leading cause of morbidity and mortality in military combat casualties so pre-injury MDR bacterial colonization is of particular concern for deployed personnel [11-13]. As such, we evaluated the rates of 
MDR organism pre- and post-travel colonization within a population of international travelers based out of San Antonio Military Medical Center (SAMMC). The objective of this pilot study was to prospectively assess antimicrobial resistance patterns and associated risk factors in bacterial colonization before and after international travel in a U.S. cohort.

\section{Methods}

\section{Study design and definitions}

Study participants included active duty personnel or Department of Defense beneficiaries $\geq 18$ years of age traveling internationally for five or more days and had been seen for a pre-travel visit at SAMMC between February 1 and November 1, 2013. Exclusion criteria included active infection at the time of enrollment (as determined by the clinical provider), inability to complete the culture swabs or questionnaire, or inability to attend a post-travel visit. At pre- and post-travel visits, subjects completed a questionnaire assessing demographics and exposures potentially related to antimicrobial resistance acquisition during travel including purpose, itinerary, accommodations, water exposure, antimicrobial exposures, hospitalizations, and illnesses. The study was reviewed and conducted as per ethical standards of the Institutional Review Board of the Brooke Army Medical Center.

\section{Bacterial susceptibility}

At the time of enrollment and within 6 weeks of return from travel, patients had culture swabs obtained from the anterior nares, oropharynx, groin, and perirectal area to determine bacterial colonization. BD CultureSwab ${ }^{\mathrm{ma}}$ $\operatorname{MaxV}(+)$ (Becton, Dickinson and Company, Franklin Lakes, NJ) was used to sample all sites for detection of bacteria. Swabs were plated onto sheep blood, MacConkey agar, and CHROMagar ${ }^{\text {Tax }}$ Staph aureus in order to isolate all gram-negative bacterial colonies and S. aureus. Colonies demonstrating morphology consistent with gramnegative or $S$. aureus were subcultured onto sheep blood agar in order to assure culture purity. All isolates were frozen at $-80{ }^{\circ} \mathrm{C}$ in Trypticase Soy Broth with $15 \%$ glycerol. Individual colonies underwent further automated testing (BD Phoenix ${ }^{\text {Th }}$ Automated Microbiology System-Becton Dickinson, Franklin Lakes, NJ) for identification and antimicrobial susceptibility testing.

Non-ESBL pre- and ESBL-producing post-travel E. coli within a subject were compared by pulsed-field gel electrophoresis (PFGE) to determine genetic relatedness. The U.S. Food and Drug Administration protocol for gram-negative rods and $\mathrm{Xba}$ I endonuclease were utilized to evaluate genotypic patterns among the isolates and subsequently group them into pulsed-field types (PFTs). Clonality was assessed using the commercial software BioNumerics
(Applied Maths, Inc., Austin, TX) and defined by $85 \%$ similarity. Multiplex PCRs were performed to determine their phylogenetic groups (A, B1, B2, C, D, E, F, Clade I) per the revised Clermont method [14].

Table 1 Overall demographics and exposures during international travel, number (\%) of subjects $(N=58)$

\begin{tabular}{|c|c|}
\hline Male gender & $24(41)$ \\
\hline Age, median (minimum-maximum) & $64(15-82)$ \\
\hline \multicolumn{2}{|l|}{ Region $^{\mathrm{a}}$} \\
\hline Mexico, Caribbean, \& Central America & $18(31)$ \\
\hline Asia & $17(29)$ \\
\hline Africa & $16(28)$ \\
\hline Europe & $5(9)$ \\
\hline South America & $2(3)$ \\
\hline North America & $2(3)$ \\
\hline \multicolumn{2}{|l|}{ Purpose of travel ${ }^{a}$} \\
\hline Vacation & $43(74)$ \\
\hline Visiting friends and relatives & $10(17)$ \\
\hline Other (missionary/volunteer) & $5(9)$ \\
\hline Deployment and military duty & $4(7)$ \\
\hline School & $1(2)$ \\
\hline $\begin{array}{l}\text { Duration of travel, median } \\
\text { (minimum-maximum) }\end{array}$ & 12 days $(6-105)$ \\
\hline \multicolumn{2}{|l|}{ Living conditions $^{a}$} \\
\hline Hotel & $36(62)$ \\
\hline Friends and relatives & $13(22)$ \\
\hline Group living ${ }^{b}$ & $10(17)$ \\
\hline Boat/cruise & $7(12)$ \\
\hline Local water ingestion during travel & $27(47)$ \\
\hline Water exposures during travel & $20(34)$ \\
\hline Antimicrobial exposure since enrollment & $23(40)$ \\
\hline Malaria chemoprophylaxis & $22(38)$ \\
\hline Atovaquone/Proguanil & $17(29)$ \\
\hline Doxycycline & $3(5)$ \\
\hline Chloroquine & $2(3)$ \\
\hline Antibiotics for traveler's diarrhea since enrollment & $3(5)$ \\
\hline Ciprofloxacin & $2(3)$ \\
\hline Erythromycin & $1(2)$ \\
\hline $\begin{array}{l}\text { Systemic antibiotics for other indications } \\
\text { since enrollment }\end{array}$ & $3(5)$ \\
\hline Azithromycin & $1(2)$ \\
\hline Cephalexin & $1(2)$ \\
\hline Unknown antibiotic & $1(2)$ \\
\hline Illness since enrollment & $13(22)$ \\
\hline Duration of illness, median (minimum-maximum) & 4 days $(1-27)$ \\
\hline
\end{tabular}

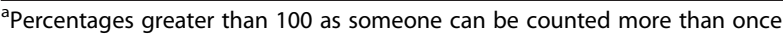
based upon region of travel or living conditions

${ }^{\mathrm{b}}$ Group living included barracks, dorms, or kibbutz 


\section{Statistical analysis}

The McNemar test was used to compare overall rates of pre- and post-travel ESBL and resistant gram-negative bacteria, $S$. aureus, and resistance to select antibacterial agents. Risk factor analysis was evaluated with $\chi^{2}$ and Fisher's exact test (when expected cell counts were less than 5) for categorical variables and Mann-Whitney $U$ for continuous variables. A $p$ value of $<0.05$ was used as a significant cutoff. Statistical analyses were performed using SPSS software (IBM ${ }^{\circ} \mathrm{SPSS}^{\circ}$ Statistics Version 19, Chicago, Illinois).

\section{Results}

\section{Demographics}

Of 58 participants, the majority were female and median age was 64 (Table 1 ). Pre- and post-travel swabs were obtained a median of ten and seven days before and after travel, respectively. The primary regions of travel were Mexico, the Caribbean, and Central America; Asia; and Africa with a median duration of travel of 12 days. The most frequent purpose of travel was vacation followed by visiting friends and relatives.

\section{E. coli colonization pre- and post-travel}

Fifty-two of 58 subjects had E. coli identified from either pre- or post-travel swabs and 36 had E. coli identified from both pre- and post-travel swabs (serial isolation) (Table 2). Multiple other notable gram-negative organisms were also isolated during screening, but none were associated with MDR or ESBL-production.

While no patients were colonized with ESBL-producing E.coli pre-travel, five (9\%) participants post-travel were colonized perirectally $(p=0.06)$ (Table 3$)$. The five ESBLproducing E.coli represented four different phylo-groups including $\mathrm{C}, \mathrm{E}, \mathrm{F}$, with two isolates from group A. None of the post-travel ESBL-producing E.coli phylo-groups matched those from non-ESBL E.coli pre-travel isolates from the same subjects. The ESBL-producing E.coli isolates were all unrelated to each other and to the pre-travel isolates from the same subjects by PFGE. There was a trend towards increased rates of ESBL-producing E.coli colonization in subjects who described their purpose of travel as missionary/volunteer $(p=0.05)$. While $40 \%$ of those with ESBL-producing E. coli colonization post-travel reported an episode of traveler's diarrhea compared to only $9 \%$ of those without ESBL-producing E. coli colonization post-travel, the results did not reach statistical significance $(p=0.1)$. There were no other significant associations between exposure risks and new ESBLproducing E.coli colonization after international travel.

\section{Antimicrobial resistance in gram-negative organisms after travel}

The ESBL-producing E.coli were universally resistant to tetracycline, trimethoprim-sulfamethoxazole (TMP/SMX), and cefazolin. Forty percent were also resistant to ciprofloxacin and gentamicin. Decreased antimicrobial susceptibility post-travel was not unique to ESBLproducing E.coli. Of 36 participants colonized with E. coli pre- and post-travel, new resistance was detected to TMP/SMX in $42 \%$ of isolates $(p<0.01)$, tetracycline in $44 \%(p<0.01)$, ampicillin-sulbactam in $33 \%(p=0.09)$, cefazolin in $19 \%$, ciprofloxacin in $17 \%$, and gentamicin in $14 \%$ of isolates after travel. While new gentamicin resistance was not significantly increased after travel, type of living conditions was associated with new gentamicin resistance $(p=0.01)$. This was primarily related to staying with friends and relatives (VFR) as $80 \%$ of subjects with new gentamicin resistance reported this exposure compared to seven percent without new gentamicin resistance $(p<0.01)$. Similarly, $67 \%$ of subjects with new ciprofloxacin resistance reported VFR during travel compared to seven percent without new ciprofloxacin resistance $(p<0.01)$. There was also a trend toward new TMP/SMX resistance in subjects who reported VFR during travel with $33 \%$ new resistance compared to five percent of those with unchanged TMP/SMX susceptibility $(p=0.06)$. New TMP/SMX resistance was also noted in $47 \%$ of those who reported illness during travel

Table 2 Bacterial colonization according to subjects and locations $(N=58)$

\begin{tabular}{|c|c|c|c|c|c|c|}
\hline \multirow[t]{2}{*}{ Organism } & \multirow{2}{*}{$\begin{array}{l}\text { No. of } \\
\text { subjects }\end{array}$} & \multirow{2}{*}{$\begin{array}{l}\text { No. of } \\
\text { isolates }\end{array}$} & \multicolumn{4}{|c|}{ Anatomic site of isolate recovery } \\
\hline & & & Nares & Oropharynx & Groin & Perirectal \\
\hline Escherichia coli & 52 & 105 & 2 & 3 & 13 & 87 \\
\hline Staphylococcus aureus & 20 & 50 & 23 & 19 & 5 & 3 \\
\hline Klebsiella species & 21 & 22 & 0 & 6 & 1 & 15 \\
\hline Enterobacter species & 9 & 12 & 2 & 5 & 1 & 4 \\
\hline Citrobacter species & 8 & 14 & 5 & 1 & 2 & 6 \\
\hline Proteus species & 8 & 13 & 0 & 0 & 2 & 11 \\
\hline Morganella morganii & 6 & 6 & 0 & 0 & 3 & 3 \\
\hline Pseudomonas aeruginosa & 5 & 6 & 0 & 3 & 3 & 0 \\
\hline Stenotrophomonas maltophilia & 4 & 5 & 0 & 1 & 1 & 3 \\
\hline
\end{tabular}


Table 3 Demographic characteristics of subjects with and without ESBL-producing E. coli acquisition during travel, number (\%) of subjects $(N=58)$

\begin{tabular}{|c|c|c|}
\hline & $\begin{array}{l}\text { Non-ESBL E. coli } \\
(n=53)\end{array}$ & $\begin{array}{l}\text { ESBL-producing } \\
\text { E. coli }(n=5)\end{array}$ \\
\hline Male gender & $23(43)$ & $1(20)$ \\
\hline Age, median (minimum-maximum) & $63(15-82)$ & $67(58-81)$ \\
\hline \multicolumn{3}{|l|}{ Region $^{a}$} \\
\hline $\begin{array}{l}\text { Mexico, Caribbean, \& Central } \\
\text { America }\end{array}$ & $17(32)$ & $1(20)$ \\
\hline Asia & $15(28)$ & $2(40)$ \\
\hline Africa & $15(28)$ & $1(20)$ \\
\hline Europe & $5(9)$ & 0 \\
\hline South America & $1(2)$ & $1(20)$ \\
\hline North America & $2(4)$ & 0 \\
\hline \multicolumn{3}{|l|}{ Purpose of travel ${ }^{a}$} \\
\hline Vacation & $40(76)$ & $3(60)$ \\
\hline Visiting friends and relatives & $10(19)$ & 0 \\
\hline Other (missionary/volunteer) ${ }^{*}$ & $3(6)$ & $2(40)$ \\
\hline Deployment and military duty & $4(8)$ & 0 \\
\hline School & $1(2)$ & 0 \\
\hline $\begin{array}{l}\text { Duration of travel, median } \\
\text { (minimum-maximum) }\end{array}$ & $12(6-105)$ & $11(7-16)$ \\
\hline \multicolumn{3}{|l|}{ Living conditions $^{a}$} \\
\hline Hotel & $33(62)$ & $3(60)$ \\
\hline Friends and relatives & $12(23)$ & $1(20)$ \\
\hline Group living $^{\mathrm{b}}$ & $9(17)$ & $1(20)$ \\
\hline Boat/cruise & $7(13)$ & 0 \\
\hline Local water ingestion during travel & $26(49)$ & $1(20)$ \\
\hline Water exposures during travel & $19(36)$ & $1(20)$ \\
\hline Antibiotic exposure since enrollment & $20(38)$ & $3(60)$ \\
\hline Malaria chemoprophylaxis & $19(36)$ & $3(60)$ \\
\hline Atovaquone/Proguanil & $14(26)$ & $3(60)$ \\
\hline Doxycycline & $3(6)$ & 0 \\
\hline Chloroquine & $2(4)$ & 0 \\
\hline $\begin{array}{l}\text { Antibiotics for traveler's diarrhea } \\
\text { since enrollment }\end{array}$ & $2(4)$ & $1(20)$ \\
\hline Ciprofloxacin & $1(2)$ & $1(20)$ \\
\hline Erythromycin & $1(2)$ & 0 \\
\hline $\begin{array}{l}\text { Systemic antibiotics for other } \\
\text { indications since enrollment }\end{array}$ & $2(4)$ & $1(20)$ \\
\hline Azithromycin & $1(2)$ & 0 \\
\hline Cephalexin & $1(2)$ & 0 \\
\hline Unknown antibiotic & 0 & $1(20)$ \\
\hline Illness since enrollment & $11(21)$ & $2(40)$ \\
\hline $\begin{array}{l}\text { Duration of illness, median } \\
\text { (minimum-maximum) }\end{array}$ & $4(1-27)$ & $5(2-8)$ \\
\hline
\end{tabular}

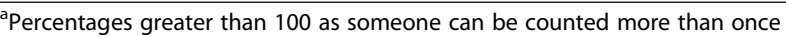
based upon region of travel or living conditions

${ }^{\mathrm{b}}$ Group living included barracks, dorms, or kibbutz ${ }^{*} p=0.05$ compared to $14 \%$ of those without illness since enrollment $(p=0.06)$.

In contrast to the risk for new acquisition of resistance, several factors associated with decreased rates of posttravel resistance were identified. Thirty-three percent of those without change in TMP/SMX resistance reported staying in group housing (including barracks, dorms, or kibbutz) versus no subjects with new TMP/SMX resistance $(p<0.01)$. Similarly, $35 \%$ of subjects without increased tetracycline resistance reported group housing during travel, compared to none with new resistance $(p<0.01)$. Sixty-five percent of those without increased tetracycline resistance compared to $25 \%$ of those with new tetracycline resistance $(p=0.02)$ and $63 \%$ of those without change in ampicillin-sulbactam susceptibility versus $17 \%$ with new ampicillin-sulbactam resistance reported local water ingestion $(p=0.01)$. Interestingly, all pre- and post-travel E. coli, including ESBL-producing E.coli, were susceptible to nitrofurantoin.

The remaining gram-negative bacterial isolates were not isolated with enough frequency to perform analysis, but in general, were susceptible to a broad range of antimicrobial agents. Of the subjects with evidence of persistent colonization, one subject had serial isolation of Klebsiella pneumoniae without increased resistance. Of the two subjects with serial Citrobacter spp. and three with Proteus spp. colonization, only one had decreased susceptibility to nitrofurantoin and another to piperacillintazobactam post-travel, respectively. No subjects had serial isolation of other gram-negative organisms.

\section{S. aureus bacterial colonization pre- and post-travel}

No participants were colonized with MRSA pre- or post-travel (Table 4). Twenty subjects had MSSA colonization during the study, with no significant difference between pre- and post-travel $(p=0.51)$. Of those with MSSA colonization, it was detected on oropharyngeal screening only in $18 \%$ of pre-travel subjects and $36 \%$ of post-travel subjects. No risk factors were identified for change in MSSA colonization (Table 5). MSSA isolates were universally susceptible to doxycycline, minocycline, and rifampin. Only two subjects were colonized with MSSA isolates resistant to clindamycin and TMP/ SMX, three to tetracycline, and one to moxifloxacin. No new resistance of colonizing MSSA strains was noted on post-travel screening.

\section{Discussion}

To further elucidate the risk factors associated with preinjury colonization with MDR gram-negative organisms in our deployed population, we first sought to evaluate the risk factors associated with MDR organism colonization in international travelers. Within this prospective pilot study, we determined that international travel was 
Table 4 Subjects with MSSA colonization, number (\%) of subjects $(N=58)$

\begin{tabular}{|c|c|c|c|c|c|}
\hline $\begin{array}{l}\text { Site of } \\
\text { Colonization }\end{array}$ & $\begin{array}{l}\text { MSSA colonization at } \\
\text { any time during study }\end{array}$ & $\begin{array}{l}\text { MSSA colonization } \\
\text { pre-travel }\end{array}$ & $\begin{array}{l}\text { MSSA colonization } \\
\text { post-travel }\end{array}$ & $\begin{array}{l}\text { McNemar } \\
p \text { value }\end{array}$ & $\begin{array}{l}\text { Acquisition or Persistence of MSSA colonization } \\
\text { between Pre- and Post-travel }\end{array}$ \\
\hline Subjects & $20(35)$ & $17(29)$ & $14(24)$ & 0.508 & $\begin{array}{l}6 \text { without persistent isolation, } 3 \text { new acquisitions } \\
\text { (11 persistent) }\end{array}$ \\
\hline Nares & $14(24)$ & $14(24)$ & $9(16)$ & 0.06 & $\begin{array}{l}5 \text { without persistent isolation, } 0 \text { new acquisitions } \\
\text { (9 persistent) }\end{array}$ \\
\hline Oropharynx & $14(24)$ & $9(16)$ & $10(17)$ & 1.00 & $\begin{array}{l}4 \text { without persistent isolation, } 5 \text { new acquisitions } \\
\text { (5 persistent) }\end{array}$ \\
\hline Groin & $5(9)$ & $4(7)$ & $1(2)$ & 0.38 & $\begin{array}{l}4 \text { without persistent isolation, } 1 \text { new acquisitions } \\
(0 \text { persistent) }\end{array}$ \\
\hline Perirectal & $3(5)$ & $2(3)$ & $1(2)$ & 1.00 & $\begin{array}{l}2 \text { without persistent isolation, } 1 \text { new acquisitions } \\
\text { ( } 0 \text { persistent) }\end{array}$ \\
\hline
\end{tabular}

associated with a trend towards increased rates of ESBLproducing E.coli colonization. Because of small numbers, no individual risk factors for ESBL-producing E.coli colonization acquisition within travel could be determined. However there were multiple risk factors, as well as protective factors, for acquisition of individual drug resistance within serial $E$. coli isolates.

Prior studies have identified international travel as a risk factor for ESBL-producing E.coli colonization, but have largely been performed in cohorts outside of the United States $[1,3,5,15-17]$. Similar to the only prior prospective study of pre- and post-travel ESBL-producing Enterobacteriaceae colonization within an American cohort (based out of New York City), the only ESBL-producing Enterobacteriaceae isolated was E. coli. Within the New York City based cohort ESBL-producing E.coli colonization increased from $2.5 \%$ pre- travel to $25 \%$ post-travel [2]. Similar post-travel rates were noted within European and Canadian travelers $[1,3,9,15]$. This is in comparison to the markedly lower rates of $0 \%$ pre- and $9 \%$ post-travel ESBL-producing E.coli noted within this study. Notably, the European and New York City based cohorts all had a higher proportion of subjects traveling to Asia and Africa, which have been shown to be areas with higher risk for ESBL-producing Enterobacteriaceae acquisition [1-3, 15]. Also notable, the study based out of New York City had a longer duration of international travel (median 21 days compared to 12 days within our cohort) [2].

Co-resistance to other antimicrobials is common with ESBL-producing E.coli. All ESBL-producing E.coli isolates were resistant to tetracycline, TMP/SMX, and cefazolin, higher than rates reported in evaluation of ESBLproducing E.coli domestically [18]. Within our post-travel ESBL-producing E.coli isolates, similar to prior studies in European travelers, there was $40 \%$ co-resistance to ciprofloxacin and gentamicin $[1,15,16]$. Reassuringly, all $E$. coli isolates remained susceptible to nitrofurantoin as data indicates that fecal flora serve as the initial source of uropathogenic E. coli $[1,19]$.
While international travel has consistently been shown to be associated with antimicrobial resistance acquisition, few specific risk factors associated with international travel have been identified. In fact, no prior studies have examined risk factors for ESBL-producing E.coli acquisition particular to travel within an American cohort. Prior studies from European and Canadian cohorts have shown location of travel to be a significant risk factor (including South and East Asia, the Indian subcontinent, Middle East, and Africa) $[1,3,7,15,16]$. A recent study also revealed the United States as a risk factor for ESBLproducing $E$. coli colonization after international travel for the first time [20]. This emphasizes the point that local resistance rates play a major role in the attributable risk of resistance acquisition of travelers. Other risk factors identified within specific cohorts include development of gastroenteritis or other gastrointestinal symptoms during travel, traveler's diarrhea, antimicrobial exposure, and older age $[1,9,16]$. Interestingly, within a Swedish cohort, all three travelers who were treated with ciprofloxacin for gastroenteritis acquired ESBL-producing E.coli on posttravel evaluation, compared to one of two subjects in our cohort [1]. As the overall post-travel ESBL-producing E.coli rate within our cohort was low, individual risk factors did not reach statistical significance. There was a trend towards those who described their purpose of travel as missionary/volunteer as having a higher rate of ESBLproducing E.coli post-travel.

Within this cohort, the ESBL-producing E.coli were from four distinct phylo-groups, none of which were identified as the dominant B2 phylo-group which has been associated with the global ST131 clone. A Canadian study of 31 post-travel ESBL-producing E.coli isolates revealed 10 were of the B2 phylo-group (8 of which were ST131 clones), 11 phylo-group A, 2 B1, and 8 phylo-group D [3]. Another study of 83 French soldiers following evacuation from overseas identified 11 ESBL-producing $E$. coli, of which eight were from the B2 and D phylo-types and three from the commensal phylo-groups A and B1 [21]. Prior studies have shown that there is a higher rate 
Table 5 Demographic characteristics of subjects with and without change in MSSA colonization, number (\%) of subjects $(N=58)^{c}$

\begin{tabular}{|c|c|c|}
\hline & $\begin{array}{l}\text { No change in } \\
\text { MSSA }(n=49)\end{array}$ & $\begin{array}{l}\text { Change in } \\
\text { MSSA }(n=9)\end{array}$ \\
\hline Male gender & $18(37)$ & $6(67)$ \\
\hline Age, median (minimum-maximum) & $64(15-82)$ & $55(18-81)$ \\
\hline \multicolumn{3}{|l|}{ Region $^{a}$} \\
\hline $\begin{array}{l}\text { Mexico, Caribbean, \& Central } \\
\text { America }\end{array}$ & $16(33)$ & $2(22)$ \\
\hline Asia & $14(29)$ & $3(33)$ \\
\hline Africa & $14(29)$ & $2(22)$ \\
\hline Europe & $4(8)$ & $1(11)$ \\
\hline South America & $1(2)$ & $1(11)$ \\
\hline North America & $2(4)$ & 0 \\
\hline \multicolumn{3}{|l|}{ Purpose of travel ${ }^{a}$} \\
\hline Vacation & $37(76)$ & $6(67)$ \\
\hline Visiting friends and relatives & $7(14)$ & $3(33)$ \\
\hline Other (missionary/volunteer) & $5(10)$ & 0 \\
\hline Deployment and military duty & $3(6)$ & $1(11)$ \\
\hline School & $1(2)$ & 0 \\
\hline $\begin{array}{l}\text { Duration of travel, median } \\
\text { (minimum-maximum) }\end{array}$ & $12(6-105)$ & $12(8-42)$ \\
\hline \multicolumn{3}{|l|}{ Living conditions $^{\mathrm{a}}$} \\
\hline Hotel & $31(63)$ & $5(56)$ \\
\hline Friends and relatives & $10(20)$ & $3(33)$ \\
\hline Group living ${ }^{b}$ & $10(20)$ & 0 \\
\hline Boat/cruise & $6(12)$ & $1(11)$ \\
\hline Local water ingestion during travel & $24(49)$ & $3(33)$ \\
\hline Water exposures during travel & $18(37)$ & $2(22)$ \\
\hline Antibiotic exposure since enrollment & $18(37)$ & $5(56)$ \\
\hline Malaria chemoprophylaxis & $17(35)$ & $5(56)$ \\
\hline Atovaquone/Proguanil & $15(31)$ & $2(22)$ \\
\hline Doxycycline & $1(2)$ & $2(22)$ \\
\hline Chloroquine & $1(2)$ & $1(11)$ \\
\hline $\begin{array}{l}\text { Antibiotics for traveler's diarrhea } \\
\text { since enrollment }\end{array}$ & $3(6)$ & 0 \\
\hline Ciprofloxacin & $2(4)$ & 0 \\
\hline Erythromycin & $1(2)$ & 0 \\
\hline $\begin{array}{l}\text { Systemic antibiotics for other } \\
\text { indications since enrollment }\end{array}$ & $3(6)$ & 0 \\
\hline Azithromycin & $1(2)$ & 0 \\
\hline Cephalexin & $1(2)$ & 0 \\
\hline Unknown antibiotic & $1(2)$ & 0 \\
\hline Illness since enrollment & $13(27)$ & 0 \\
\hline $\begin{array}{l}\text { Duration of illness, median } \\
\text { (minimum-maximum) }\end{array}$ & $4(1-27)$ & $\mathrm{n} / \mathrm{a}$ \\
\hline
\end{tabular}

apercentages greater than 100 as someone can be counted more than once based upon region of travel or living conditions

${ }^{\mathrm{b}} \mathrm{Group}$ living included barracks, dorms, or kibbutz

${ }^{c}$ No statistically significant differences identified between the two groups of persistent colonization, traveler's diarrhea, and extraintestinal infections with the more virulent B2 and D phylo-groups compared with commensal E. coli phylogroups [14, 17, 19, 22-24]. It should be noted that these studies were not performed with the recently revised Clermont E. coli phylo-typing method which was used for this study which identifies eight phylo-groups rather than four (though likely does not affect isolates previously assigned to B1 and B2 phylo-groups) [14]. A recent study evaluating UTI-associated E. coli isolates with the revised Clermont method revealed a more heterogeneous sample than previously thought with only $56 \%$ of the isolates belonging to $\mathrm{B} 2$ and D phylo-groups and $32 \%$ of the urine isolates from lineages $\mathrm{A}, \mathrm{B} 1$, and $\mathrm{E}$ [25]. The fact that post-travel ESBL-producing E.coli isolates were unrelated to pre-travel isolates in the four patients with serial E. coli isolation could represent new strain acquisition, or polymicrobial colonization which was not captured by the choice of single isolates for testing (though morphologically distinct appearing colonies were evaluated).

Similar to prior studies, there was a significant decrease in antimicrobial susceptibility of $E$. coli isolates post-travel [26-28]. Among E. coli isolates, there was a statistically significant decrease in TMP/SMX and tetracycline susceptibilities, as well as a trend toward decreased ampicillinsulbactam susceptibility. Prior studies have shown similar rates of TMP/SMX resistance post-travel [26, 27]. Visiting friends and relatives was associated with increased ciprofloxacin and gentamicin resistance during travel. This is of particular concern as ciprofloxacin and gentamicin resistance has been associated with prolonged carriage in prior studies of travelers, with up to ten percent of participants still harboring ciprofloxacin or gentamicin resistance at six months following travel [17].

Interestingly, both group housing and local water ingestion during travel were associated with decreased acquisition of antimicrobial resistance during travel, particularly to ampicillin-sulbactam and tetracycline. Similar findings were noted in a study by Kennedy and Collignon who reported that returning without resistant $E$. coli was statistically associated with consumption of water that was not bottled or boiled [26].

Unlike a prior study of US- and Afghanistan-based military personnel, no MRSA was detected at any point [29]. As in prior studies, recovery of $S$. aureus was increased by extra-nares screening [30,31]. Eighteen percent of pretravel and $36 \%$ of post-travel $S$. aureus isolates were recovered from only the oropharynx. Also differing from the prior military population where the US-based personnel had higher rates of oropharyngeal colonization, rates of oropharyngeal colonization increased from $53 \%$ pre-travel to $72 \%$ post-travel within our cohort [29].

Limitations of our study include the small cohort size and subsequent low rate of ESBL-producing E. coli 
colonization. Additionally, there were relatively few travelers to previously identified high risk regions for resistance acquisition. These factors led to decreased power to detect individual risk factors for antimicrobial resistance acquisition. Because the median age of our study population is 64 years, this limits applicability of these findings to our active duty military population, but does make it more generalizable to the average international traveler. Screening for ESBL-producing E. coli colonization was performed with perirectal swabs rather than stool culture, the gold standard, which may have decreased yield. However, Lautenbach et al. have shown the sensitivity of perirectal swabs compared to stool samples for identification of resistant gram-negative bacilli to be $90 \%$. They also showed that perirectal swabs were in complete agreement with rectal swabs and were most likely to be falsely negative when the burden of resistant gram-negatives within stool culture was very low [32]. Use of rectal swabs has been used successfully in similar prior studies [15].

\section{Conclusion}

Overall, our findings support those seen in prior studies, with increased rates of antimicrobial resistance following international travel. Visiting friends and relatives was associated with acquisition of resistance to various antimicrobials including ciprofloxacin, one of the first line antimicrobials for treating $E$. coli infections. While, traveler's diarrhea has been shown to not only be associated with an average 24-h period of disability, but also longterm complications including persistent or intermittent gastrointestinal symptoms in a minority of travelers (including subsequent diagnosis of irritable bowel syndrome in between five and ten percent), its occurrence as well as treatment has been associated with increased risk of antimicrobial resistance acquisition $[1,9,16,33]$. Further elucidation of risks for antimicrobial resistance acquisition while traveling will better enable providers to counsel their patients regarding risks of travel. It will also allow providers to further balance the risks and benefits of empiric treatment of traveler's diarrhea with antimicrobials [34]. Reassuringly, our rates of ESBLproducing E.coli acquisition were significantly lower than those seen in other studies of international travelers. Larger, prospective studies are needed to further define individual risk factors particular to travel which are associated with ESBL-producing Enterobacteriaceae acquisition.

\section{Abbreviations}

ESBL: extended-spectrum $\beta$-lactamase; MDR: multidrug-resistant; MRSA: methicillin-resistant S. aureus; PR: peri-rectal; PFGE: pulsed-field gel electrophoresis; SAMMC: San Antonio military medical center; PFTs: pulsed-field types; TMP/SMX: trimethoprim-sulfamethoxazole; VFR: staying with friends and relatives.
Competing interests

The authors declare that they have no competing interests.

\section{Authors' contributions}

DB participated in PFGE analysis, data analysis, and manuscript preparation. KM performed the isolate identification, susceptibility testing, PFGE, and helped draft the manuscript. AM participated in design and coordination and helped to draft the manuscript. MB performed the isolate identification, susceptibility testing, and PFGE analysis. KH helped with data collection and interviews. CR helped with data collection and interviews. WZ performed the isolate identification, susceptibility testing, and PFGE analysis. CM participated in the design and coordination of the study, aided with data analysis, and manuscript preparation. KA participated in the design and coordination of the study and manuscript preparation. All authors read and approved the final manuscript.

\section{Disclaimer}

The Views expressed are those of the author(s) and do not necessarily reflect the official views of Brooke Army Medical Center, the U.S. Army Medical Department, the U.S. Army Office of the Surgeon General, the Department of the Army, the Uniformed Services University of the Health Sciences, or the Department of Defense.

\section{Author details}

${ }^{1}$ Infectious Disease Service, San Antonio Military Medical Center, JBSA Fort Sam Houston, 3551 Roger Brooke Drive, Houston, Texas 78234-4505, USA. ${ }^{2}$ Infectious Disease Clinical Research Program, Uniformed Services University of the Health Sciences, Bethesda, Maryland, USA. ${ }^{3}$ The Henry M. Jackson Foundation for the Advancement of Military Medicine, Inc., Bethesda, Maryland, USA. ${ }^{4}$ Pediatric Infectious Disease Service, San Antonio Military Medical Center, JBSA Fort Sam Houston, Houston, Texas, USA. ${ }^{5}$ U.S. Army Institute for Surgical Research, JBSA Fort Sam Houston, Houston, Texas, USA.

Received: 7 January 2016 Accepted: 20 February 2016

Published online: 14 March 2016

\section{References}

1. Tangden T, Cars O, Melhus A, Lowdin E. Foreign travel is a major risk factor for colonization with Escherichia coli producing CTX-M-type extendedspectrum beta-lactamases: a prospective study with Swedish volunteers. Antimicrob Agents Chemother. 2010;54:3564-8.

2. Weisenberg SA, Mediavilla JR, Chen L, Alexander EL, Rhee KY, Kreiswirth BN, Jenkins SG. Extended spectrum beta-lactamase-producing

Enterobacteriaceae in international travelers and non-travelers in New York City. PLoS One. 2012;7:e45141.

3. Peirano G, Laupland KB, Gregson DB, Pitout JD. Colonization of returning travelers with CTX-M-producing Escherichia coli. J Travel Med. 2011;18:299-303

4. Laupland KB, Church DL, Vidakovich J, Mucenski M, Pitout JD. Communityonset extended-spectrum beta-lactamase (ESBL) producing Escherichia coli: importance of international travel. J Infect. 2008;57:441-8.

5. Freeman JT, McBride SJ, Heffernan H, Bathgate T, Pope C, Ellis-Pegler RB. Community-onset genitourinary tract infection due to CTX-M-15-Producing Escherichia coli among travelers to the Indian subcontinent in New Zealand. Clin Infect Dis. 2008;47:689-92.

6. van der Bij AK, Pitout JD. The role of international travel in the worldwide spread of multiresistant Enterobacteriaceae. J Antimicrob Chemother. 2012; 67:2090-100

7. Ruppe E, Armand-Lefevre L, Estellat C, Consigny PH, El Mniai A, Boussadia Y, Goujon C, Ralaimazava P, Campa P, Girard PM, et al. High rate of acquisition but short duration of carriage of multidrug-resistant Enterobacteriaceae after travel to the tropics. Clin Infect Dis. 2015:61:593.

8. Epelboin L, Robert J, Tsyrina-Kouyoumdjian E, Laouira S, Meyssonnier V, Caumes E, Group M-GTW, et al. High rate of multidrug-resistant gramnegative bacilli carriage and infection in hospitalized returning travelers: a cross-sectional cohort study. J Travel Med. 2015;22:292.

9. Kantele A, Laaveri T, Mero S, Vilkman K, Pakkanen SH, Ollgren J, Antikainen J, Kirveskari J. Antimicrobials increase travelers' risk of colonization by extendedspectrum betalactamase-producing Enterobacteriaceae. Clin Infect Dis. 2015;60:837-46. 
10. Vento TJ, Cole DW, Mende K, Calvano TP, Rini EA, Tully CC, Zera WC, Guymon $\mathrm{CH}, \mathrm{Yu}$ X, Cheatle KA, et al. Multidrug-resistant gram-negative bacteria colonization of healthy US military personnel in the US and Afghanistan. BMC Infect Dis. 2013;13:68.

11. Holcomb JB, McMullin NR, Pearse L, Caruso J, Wade CE, Oetjen-Gerdes L, Champion HR, Lawnick M, Farr W, Rodriguez S, Butler FK. Causes of death in U.S. Special Operations Forces in the global war on terrorism: 2001-2004. Ann Surg. 2007;245:986-91.

12. Kelly JF, Ritenour AE, McLaughlin DF, Bagg KA, Apodaca AN, Mallak CT, Pearse L, Lawnick MM, Champion HR, Wade CE, Holcomb JB. Injury severity and causes of death from operation Iraqi freedom and operation enduring freedom: 2003-2004 versus 2006. J Trauma. 2008;64:S21-6. discussion S26-27.

13. Tribble DR, Conger NG, Fraser S, Gleeson TD, Wilkins K, Antonille T, Weintrob A, Ganesan A, Gaskins L, Li P, et al. Infection-associated clinical outcomes in hospitalized medical evacuees after traumatic injury: trauma infectious disease outcome study. J Trauma. 2011;71:S33-42.

14. Clermont O, Christenson JK, Denamur E, Gordon DM. The Clermont Escherichia coli phylo-typing method revisited: improvement of specificity and detection of new phylo-groups. Environ Microbiol Rep. 2013;5:58-65.

15. Paltansing S, Vlot JA, Kraakman ME, Mesman R, Bruijning ML, Bernards AT, Visser LG, Veldkamp KE. Extended-spectrum beta-lactamase-producing enterobacteriaceae among travelers from the Netherlands. Emerg Infect Dis. 2013;19:1206-13.

16. Ostholm-Balkhed A, Tarnberg M, Nilsson M, Nilsson LE, Hanberger H, Hallgren A, Travel Study Group of Southeast S. Travel-associated faecal colonization with ESBL-producing Enterobacteriaceae: incidence and risk factors. J Antimicrob Chemother. 2013;68:2144-53.

17. Rogers BA, Kennedy KJ, Sidjabat HE, Jones M, Collignon P, Paterson DL. Prolonged carriage of resistant E. coli by returned travellers: clonality, risk factors and bacterial characteristics. Eur J Clin Microbiol Infect Dis. 2012;31:2413-20.

18. Doi Y, Park YS, Rivera JI, Adams-Haduch JM, Hingwe A, Sordillo EM, Lewis JS 2nd, Howard WJ, Johnson LE, Polsky B, et al. Communityassociated extended-spectrum beta-lactamase-producing Escherichia coli infection in the United States. Clin Infect Dis. 2013;56:641-8.

19. Moreno E, Andreu A, Pigrau C, Kuskowski MA, Johnson JR, Prats G. Relationship between Escherichia coli strains causing acute cystitis in women and the fecal E. coli population of the host. J Clin Microbiol. 2008;46:2529-34

20. Reuland EA, Al Naiemi N, Kaiser AM, Heck M, Kluytmans JA, Savelkoul PH, Elders PJ, Vandenbroucke-Grauls CM. Prevalence and risk factors for carriage of ESBL-producing Enterobacteriaceae in Amsterdam. J Antimicrob Chemother. 2016; Epub ahead of print

21. Janvier F, Delacour H, Tesse S, Larreche S, Sanmartin N, Ollat D, Rapp C, Merens A. Faecal carriage of extended-spectrum beta-lactamase-producing enterobacteria among soldiers at admission in a French military hospital after aeromedical evacuation from overseas. Eur J Clin Microbiol Infect Dis. 2014;33:1719-23.

22. Bailey JK, Pinyon JL, Anantham S, Hall RM. Distribution of human commensal Escherichia coli phylogenetic groups. J Clin Microbiol. 2010;48: 3455-6.

23. Russo TA, Johnson JR. Proposal for a new inclusive designation for extraintestinal pathogenic isolates of Escherichia coli: ExPEC. J Infect Dis. 2000;181:1753-4.

24. Guiral E, Mendez-Arancibia E, Soto SM, Salvador P, Fabrega A, Gascon J, Vila J. CTX-M-15-producing enteroaggregative Escherichia coli as cause of travelers' diarrhea. Emerg Infect Dis. 2011;17:1950-3.

25. Toval F, Kohler CD, Vogel U, Wagenlehner F, Mellmann A, Fruth A, Schmidt MA, Karch H, Bielaszewska M, Dobrindt U. Characterization of Escherichia coli isolates from hospital inpatients or outpatients with urinary tract infection. J Clin Microbiol. 2014;52:407-18.

26. Kennedy K, Collignon P. Colonisation with Escherichia coli resistant to "critically important" antibiotics: a high risk for international travellers. Eur J Clin Microbiol Infect Dis. 2010;29:1501-6.

27. Murray BE, Mathewson JJ, DuPont HL, Ericsson CD, Reves RR. Emergence of resistant fecal Escherichia coli in travelers not taking prophylactic antimicrobial agents. Antimicrob Agents Chemother. 1990;34:515-8.

28. Colgan R, Johnson JR, Kuskowski M, Gupta K. Risk factors for trimethoprimsulfamethoxazole resistance in patients with acute uncomplicated cystitis. Antimicrob Agents Chemother. 2008:52:846-51.
29. Shaw AG, Vento TJ, Mende K, Kreft RE, Ehrlich GD, Wenke JC, Spirk T, Landrum ML, Zera W, Cheatle KA, et al. Detection of methicillin-resistant and methicillin-susceptible Staphylococcus aureus colonization of healthy military personnel by traditional culture, PCR, and mass spectrometry. Scand J Infect Dis. 2013;45:752-9.

30. McKinnell JA, Huang SS, Eells SJ, Cui E, Miller LG. Quantifying the impact of extranasal testing of body sites for methicillin-resistant Staphylococcus aureus colonization at the time of hospital or intensive care unit admission. Infect Control Hosp Epidemiol. 2013;34:161-70.

31. Ide L, Lootens J, Thibo P, Infection Control Team of the Jan Palfijn Ziekenhuis $\mathrm{G}$. The nose is not the only relevant MRSA screening site. Clin Microbiol Infect. 2009;15:1192-3.

32. Lautenbach E, Harris AD, Perencevich EN, Nachamkin I, Tolomeo P, Metlay JP. Test characteristics of perirectal and rectal swab compared to stool sample for detection of fluoroquinolone-resistant Escherichia coli in the gastrointestinal tract. Antimicrob Agents Chemother. 2005;49:798-800.

33. de la Cabada BJ, Dupont HL. New developments in traveler's diarrhea. Gastroenterol Hepatol (N Y). 2011;7:88-95.

34. Connor BA, Keystone JS. Editorial commentary: antibiotic self-treatment of travelers' diarrhea: helpful or harmful? Clin Infect Dis. 2015;60:847-8.

\section{Submit your next manuscript to BioMed Central and we will help you at every step:}

- We accept pre-submission inquiries

- Our selector tool helps you to find the most relevant journal

- We provide round the clock customer support

- Convenient online submission

- Thorough peer review

- Inclusion in PubMed and all major indexing services

- Maximum visibility for your research

Submit your manuscript at www.biomedcentral.com/submit
Ciomed Central 